\title{
ACERCA DE LA VIOLENCIA SIMBÓLICA EN LAS RELACIONES INTERGENÉRICAS DE ADOLESCENTES
}

Maiber Solarte Muñoz Paula Andrea Ortiz Duque 


\title{
RESUMEN
}

\begin{abstract}
El lenguaje verbal permite acercarnos a las representaciones que los y las adolescentes configuran de acuerdo a los apelativos usados en las relaciones intergenéricas, con lo cual se puedo comprobar la existencia de jerarquías respecto a la mujer, estereotipos y el temor a la exclusión, fundamentos de la violencia simbólica.
\end{abstract}

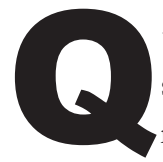

uizá a los pocos acuerdos a los que se ha llegado en los estudios realizados sobre el fenómeno de la violencia es aceptar su carácter polifórmico ${ }^{1}$. Se ha mencionado la existencia e incluso coexistencia de distintas variantes y manifestaciones de lo violento. La violencia como manifestación de crisis en las normas de convivencia social, puede examinarse en el ámbito de las relaciones de género, teniendo en cuenta sus efectos en las mujeres de nuestro país. El discurso formal que promulga la igualdad de condiciones entre hombres y mujeres y las garantías ciudadanas otorgadas a la mujer, se confronta con la situación real que exige voluntad política del Estado para mejorarlas y responsabilidades de la sociedad civil para velar por la promoción, difusión y respeto a los derechos humanos, convirtiéndose en un espacio propicio para la intervención de los trabajadores sociales.

Fue esta la principal razón que motivó el desarrollo del trabajo de investigación denominado Violencia simbólica: Una perspectiva de género acerca del lenguaje usado en la escuela. El presente artículo expone algunas de las consideraciones conceptuales que se tuvieron en cuenta y de manera sintética los hallazgos más importantes obtenidos en el estudio, en el cual se exploró la forma en que el lenguaje verbal utilizado por los adolescentes hombres para referirse a las mujeres, demostraba el ejercicio de la violencia simbólica.

${ }^{1}$ CAMACHO, A., GUZMÁN, A. (1997). "La violencia urbana en Colombia: Teorías, modalidades, perspectivas", en Nuevas visiones sobre la violencia en Colombia. Bogotá IEPRIFESCOL, Pág. 19 
Cada sociedad fabrica las imágenes o expectativas, es decir el universo simbólico que da sentido al actuar de hombres y mujeres en la vida cotidiana; se trata de modelos a los que se deben ajustar los individuos para cumplir con pautas de conducta esperables que se expresan y reproducen a través de mitos, ideologías o representaciones sociales que marcan las relaciones de género.

En esta perspectiva, "el concepto de género comprende imaginarios, que simbolizan y dan sentido a la diferencia sexual, a la manera como se explican, valoran y establecen normas acerca de la masculinidad o la feminidad. Los imaginarios en torno a las relaciones de género inscriben a los individuos en unas características culturales específicas a partir de las diferencias biológicas, incidiendo en la formación de las identidades de varones y mujeres desde que se nace y en sus comportamientos en el curso de la vida"2.

De ésta manera, la cultura occidental establece una lógica binaria que opone lo femenino a lo masculino sobrevalorando el rol de los hombres: el espacio público, la racionalidad, la fuerza, la competencia y, desvalorizando el de la mujer: el espacio privado, la emocionalidad, la docilidad, pasividad y sumisión. Dicha jerarquización reproduce relaciones de poder fundamentadas en una cultura patriarcal. Esas estructuras mentales poseen imágenes y esquemas jerarquizados demostrados en relaciones dominado-dominante cotidianas y naturalizadas; la realidad social que produce esa dominación acaba a menudo por confirmar las imágenes y esquemas que defiende para realizarse y significarse.

Bourdieu define la violencia simbólica, como la violencia que se ejerce sobre un agente social con su complicidad o consentimiento, y señala también que la forma paradigmática de la violencia simbólica es la lógica de la dominación de género. La violencia simbólica se instituye a través de la adhesión que el dominado se siente obligado a conceder al dominante, y por consiguiente, a la dominación.

Es así como, las mujeres quedan sujetas a estructuras mentales que son el producto de la asimilación de relaciones de poder y jerarquías que encuentran facilidad para ser acogidas en la objetividad de un sentido común. Se podría decir también que la violencia simbólica es la posibilidad o "capacidad de imponer mediante arbitrarios un arbitrario cultural, disimulando el doble carácter arbitrario de su imposición”, de imponer sentidos o significaciones. La imposición es aparente, no opera con coacciones externas ni brutales, ella es ejercida sobre "un agente social" con la anuencia de este".

Esta complacencia o complicidad se explica porque este agente social -la mujer- está inmerso en la lógica, mecanismos y estrategias de dominación. Este agente social acepta las estrategias y las comparte de manera inconsciente, recubriendo a la violencia simbólica de naturalidad. Estos mecanismos han sido adquiridos, es decir, aprendidos, y construidos

\footnotetext{
${ }^{2}$ CASTORADIS, C. (1975). La institución imaginaria de la sociedad. Tusquets editores. Barcelona. Pág. 97

${ }^{3}$ PROSS, H.. (1979). Violencia de los símbolos sociales. Editorial Antrhopos. España. Pág. 122.

${ }^{4}$ BOURDieU, P. (2000). La dominación masculina. Editorial Anagrama, Barcelona. Pág. 49 
socialmente, pero se han encarnado porque hacen parte del entramado de dispositivos que regulan los órdenes sociales, luchas, los intercambios, y la vida misma del sujeto.

Debido a que el fundamento de la violencia simbólica no reside en las conciencias engañadas que bastaría con iluminar, sino en unas inclinaciones modeladas por las estructuras de dominación que las producen, la ruptura de la relación de complicidad que las víctimas de la dominación simbólica conceden a los dominadores sólo puede esperarse de una transformación radical de las condiciones sociales de producción de las inclinaciones que llevan a los dominados a adoptar sobre los dominadores y sobre ellos mismos un punto de vista idéntico al de los dominadores.

La eficacia de la violencia simbólica radica en la validez que para los agentes sociales dominados tengan los símbolos o significaciones que se intentan imponer, defender o instaurar.

La violencia simbólica tiene distintas formas de manifestarse. Existen violencias simbólicas cronotópicas, de estereotipos y de pertenencia que se circunscriben en los esquemas mentales y se perpetran por medio de las conductas.

- VIOLENCIAS SIMBÓliCAS CRONOTÓpiCAS: Estas violencias se definen a partir de dos elementos principales: por una parte, la temporalidad (cronos), y por otra, el espacio (topos). Se expresan al excluir a un sujeto de determinados espacios, al limitar su desplazamiento y desarrollo y al negar la corporeidad presente. Pero a la vez, estas violencias se expresan al restringir las etapas de los sujetos, los ritmos de crecimiento y desarrollo o al castigar a los individuos por haber incumplido los tiempos establecidos para determinados rituales. ${ }^{5}$

- VIOLENCIAS SimbóliCAS DE ESTEREOTIPOs: Los estereotipos, para este caso, se desarrollan sobre los roles sexuales, en ellos se incluyen conceptos específicos respecto al aspecto aprobado, incluyendo la constitución corporal, los rasgos faciales y la ropa: patrones aprobados de conducta, modos adecuados de hablar, métodos para expresar sentimientos y emociones, para ganarse la vida y muchas otras cualidades. ${ }^{6}$ Una vez que se forman, estos estereotipos actúan como normas que sirven para que a cada individuo lo juzguen los miembros del grupo social como apropiado o no para su sexo. Sirven también como normas de auto evaluación, las personas se consideran ellas mismas, por el modo en que sus cualidades se califican en función de las normas establecidas en el estereotipo. Todos los aspectos de un estereotipo se combinan para crear una actitud rígida de juicio y distanciamiento hacia los individuos que no se conforman al patrón estereotipado. ${ }^{7}$

\footnotetext{
${ }^{5}$ RODRIGUEZ, A., VILLEGAS, P. (2000). "Mujeres y relatos de violencia simbólica”. Tesis Comunicación Social, Universidad del Valle. Pág. 144.

${ }^{6}$ HURLOCK, E. (1970). Desarrollo del niño. Mc. Graw Hill. México. Pág. 487.

${ }^{7}$ Ibidem. Pág. 487.
} 
- Violencias simbólicas asociadas a la pertenencia: En la pertenencia al grupo, el sujeto configura auto imágenes, filiaciones, se siente amado, reconocido confiado, se realiza en la relación con otros, efectúa posibilidades que el grupo favorece, aunque en ocasiones también las inhiba. Por el contrario, al sentirse excluido se resquebraja su propia imagen, experimenta vacíos, impotencias, siempre y cuando el grupo que lo excluye sea importante o significativo para el sujeto. La exclusión actúa como potencialidad y posibilidad; el temor a no pertenecer, a ser abandonados, eliminados, en otras palabras, a ser desvinculados simbólicamente.

En especial, en la adolescencia, se determinan roles sexuales socialmente definidos que reflejan conductas y actitudes que se aceptan en general dentro de una cultura como masculinos o femeninos. El repertorio amplio de discursos -lenguaje verbal- y prácticas utilizados en la adolescencia, requiere de un aprendizaje largo y sistemático en el que se articulen, o conjuguen discursos, agentes sociales y campos considerados como válidos o legítimos por el sujeto. La violencia simbólica se manifiesta en sus diferentes tipos, de acuerdo a la imagen o aspecto evocado por el lenguaje verbal utilizado por los y las adolescentes

El estudio desarrollado tomó como base para el análisis un corpus de palabras utilizadas por los adolescentes para referirse a las mujeres, ellas fueron: mami, bagre, barbie, buena, diabla, niña, hembra, gorda, coqueta, chiquita, flaca, bombom, negrita, cosita, cariño. Estos términos prefiguran representaciones que no sólo se quedan en el campo de lo simbólico, se radican en la mentalidad del individuo, sea que se ubique en la posición de dominado o dominante.

La lógica de la dominación estructura esquemas e interpretaciones jerarquizados que se confirman en el contexto, con su relación y significación "el efecto de la dominación, es especial de la dominación simbólica se produce a través de los esquemas de percepción, de apreciación y de acción que constituyen los hábitos"».

El ejercicio de la violencia simbólica opera soterradamente del inconsciente de un individuo al de otro, actuando colectivamente. Una sociedad cuando se instituye como tal "inventa significaciones; estas producciones de sentido, de sentido organizador, no están para representar otra cosa sino que estos esquemas organizadores son condición de representabilidad de aquello que esa sociedad puede darse. Lo que mantiene unida a una sociedad es su institución, dice Castoriadis, es decir, el proceso por el cual la sociedad se instituye como totalidad, las normas, los valores y el lenguaje instituido no son solo herramientas o procedimientos para hacer frente a las cosas sino más bien son los instrumentos para hacerlas; en particular, para hacer individuos"9

${ }^{8}$ BOURDIEU, P. (2000). La dominación masculina. Editorial Anagrama, Barcelona. Pág. 50.

${ }^{9}$ FERNÁNDEZ, A. (1993). La mujer de la ilusión Pactos y contratos entre hombres y mujeres (compilación). Editorial Paidós. Buenos Aires Argentina. Pág. 241-242. 
De esta manera, tanto hombres como mujeres sesgamos la realidad; a partir de esto, determinando el uso de términos para referirse a las mujeres. Ya sea, desde el grupo de hombres o de mujeres se demuestra la naturalización de la violencia simbólica y la incorporación a nuestras vidas de las estructuras dominantes.

Se violenta al otro al intentar imponer un rol, un modelo mental simplificado y rígido sobre sí mismo(a), ó de igual manera, porque el sujeto haya incorporado un estereotipo y éste se autocensura para evitar su resquebrajamiento. De esta manera, se puede caracterizar lo anterior como la primera manifestación de la violencia simbólica: los estereotipos.

En los estereotipos parecen arraigarse fuertemente las violencias simbólicas. Un estereotipo que actúa como una representación rígida de sí, es incorporada por el sujeto, constriñendo otras formas posibles de vida, de auto representación.

Discursos cotidianos de la familia patriarcal y androcéntrica, y discursos provenientes de la escuela (grupo de pares) y las religiones parecen haber esculpido una representación de lo que él o ella deben ser y hacer. De este modo, el principio de perpetuación de esta forma de dominación "no reside solamente, en uno de los lugares más visibles de su ejercicio, es decir, en la unidad doméstica, sino en instancias como la escuela o el Estado, lugares de elaboración e imposición de los principios de dominación". ${ }^{10}$

Para engendrar los estereotipos se requiere de un aprendizaje largo y sistemático en el que se articulen, o conjuguen variados discursos, agentes sociales y campos considerados como legítimos por el sujeto. "Dicha arbitrariedad cultural es una pieza clave en los sistemas de dominación; los diferentes dispositivos institucionales hacen posible que esta arbitrariedad cultural sea reconocida como legítima y al mismo tiempo otorga legitimidad al grupo dominador como autoridad."11

Por lo tanto, y en consonancia con la incorporación del rol femenino, el lenguaje verbal también encauza hacia la introyección de los esquemas jerarquizados producto de estas representaciones.

De modo que todas las palabras referenciadas en el corpus: mami, bagre, barbie, buena, diabla, niña, hembra, coqueta, chiquita, flaca, bombom, negrita, gorda, cosita y cariño, cumplen con el fin de un estereotipo, imponer un rol, un modelo mental simplificado y rígido que según la palabra prefigura:

- Su comportamiento o al menos el supuesto de su conducta (diabla, coqueta).

- De acuerdo al aspecto físico (barbie, buena, bagre, hembra, bombom, gorda, flaca y negrita)

- También la actitud y/o comportamiento (mami, niña)

\footnotetext{
${ }^{10}$ Égalité homme - femme ? Origine et aspects de la discrimination sur le marché du travail. La construction des rapports sociaux entre les sexes. En : www.webomatique.com/mst/ bourdieu_dom_bocquet.htm
} 
- Y al establecimiento de relaciones afectivas y su desarrollo (chiquita, cosita y cariño)

Por consiguiente, los estereotipos y sus roles se activan con fuerza hasta instalarse en el interior del sujeto proclamándolo como un comportamiento naturalizado.

Se ha dicho que "durante la adolescencia, los sujetos se esfuerzan por darle sentido al ser y al mundo y ello se logra en gran medida por la relación que se establece con los pares que reafirman o desvirtúan lo que se piensa de si mismo y del entorno"12

Los adolescentes se sienten continuamente examinados por las personas que conocen y creen que todos son sus críticos o sus admiradores en la misma forma en que ellos son críticos y admiradores de sí mismos y de los demás. En consecuencia, se busca proyectarse tal como quisiera que otros los reconocieran y por ello, adoptan las actitudes que el grupo juzga como positivas y se rechazan aquellas que son de la displicencia de éste.

En el estudio se pudo observar, cómo los adolescentes participantes, no sólo reconocen cuáles son las conductas aceptables o no, sino que en el caso de las mujeres, se juzga a quienes actúan de un modo particular connotado negativamente y al mismo tiempo, se teme ser denominada en forma negativa. Por ejemplo, las adolescentes acusan y ejercen críticas sobre otras que se comportan en una forma determinada como "diablas", pero también les preocupa ser llamadas así.

Es así como, la imagen corporal, la actitud y la conducta adquieren una gran importancia en la consolidación de la identidad que se refuerza con la aprobación o censura de los pares. "Los adolescentes se examinan constantemente unos a otros con mucha atención y reparando hasta el último detalle: observan y comentan" ${ }^{13}$, sus comentarios pueden llegar a ser crueles, pero eso les es necesario para legitimar sus preocupaciones por ellos mismos, se establece una comparación con el otro en la que "yo gano, soy mejor".

Por medio de la crítica, los adolescentes se auto protegen, pues en la medida en que se tiene la autoridad para juzgar al otro, se está demostrando que uno no actúa en determinada manera, que "eso no es para mi" y que por tanto, no se puede ser juzgado.

La etapa de la adolescencia "supone para todos los jóvenes (chicos y chicas) confluencia de cambios de muy diversa índole que incluyen las consecuencias anatomofisiológicas de la pubertad, comprende asimismo importantes marcadores o reforzadores de género". ${ }^{14}$

La mayoría de los adolescentes de ambos sexos se preocupan más de su apariencia física que de cualquier otro aspecto personal y en este marco, hay cosas que llaman más

${ }^{11}$ FERNÁNDEZ, A. (1993). La mujer de la ilusión Pactos y contratos entre hombres y mujeres (compilación). Editorial Paidós. Buenos Aires Argentina. Pág. 115.

${ }^{12}$ PAPALIA, D., OLDS, S. (1979). Sicología del desarrollo. Editorial Mc Graw Hill. México, Pág. 375.

${ }^{13}$ Ibidem.

${ }^{14}$ SÁENZ, C. (1990). "Violencia y proceso de socialización genérica: enajenación y trasgresión, dos alternativas extremas para las mujeres". Violencia y sociedad patriarcal. Editorial Pablo Iglesias. Madrid. Pág. 43. 
su atención. Las mujeres quieren ser delgadas pero con busto (barbie, buena) y cualquier cosa que les haga pensar que su apariencia es masculina como un marco facial anguloso con vello en la cara (bagre) hará que se sientan inconformes.

De acuerdo a la caracterización de la violencia simbólica, encontramos como segunda manifestación: violencias cronotópicas (crono = tiempo, topo = lugar, espacio).

El tiempo connota edad, ciclos biológicos, rituales sociales, periodos asociados a determinadas temporalidades. En consecuencia, el control de espacios y tiempo contribuye a reforzar la invisibilización, borrar al otro, hacerlo invisible a los ojos, corroborando el fenómeno de la violencia simbólica. Esta regulación de la temporalidad y la espacialidad, asigna tiempos y lugares que coaccionan el cuerpo, la mente y el desarrollo de hombres y mujeres.

De esta manera, palabras como "niña" y "chiquita" evocan ciclos de vida detenidos (niña) y desarrollo humano obstaculizado (chiquita), procurando de manera empírica un control y una existencia regulada de forma que el cuerpo adulto se invisibiliza proponiendo la imagen de inocencia y pequeñez arbitrariamente, que refleja una vez más la connotación de violencia simbólica.

La exclusión actúa en lugares y espacios, como anteriormente se mencionó, pero también se constituye en los grupos humanos. Con este motivo aparecen las violencias simbólicas que están asociadas a la pertenencia, como tercera manifestación de este fenómeno. La exclusión actúa como potencialidad y posibilidad; la amenaza explícita o tácita de la exclusión aparece reviviendo el temor a ser expulsados(as), a ser abandonados(as), de no pertenecer, de ser eliminados de cualquier grupo proyectando la desvinculación simbólica. El temor a la exclusión como capacidad y posibilidad es frecuente, es así como esta categoría se ubica en el núcleo más fuerte de las violencias simbólicas.

Pero estas dinámicas entre exclusión y pertenencia suscitan varios movimientos ambivalentes. Por un lado, el deseo de ser reconocidos(as), y mas que aceptados (as), de pertenecer al grupo dominante, de compartir sus expectativas, de imitar los comportamientos, de compartir rituales; pero al mismo tiempo provoca rechazo hacia las mismas, hacia lo que no son y que arbitrariamente le asignaron, sentimientos de incompetencia y derrota. Pero de otro lado procura sentimiento, rechazo hacia quienes los y las rechazan tal como son, hacia quienes los y las agreden física y simbólicamente (burlas, apodos y actitudes provocadoras).

En este caso, las violencias que demarcan el afuera y el adentro, estarían contribuyendo a erosionar la auto imagen de las mujeres referenciadas. Palabras como "cariño" promueven el alejamiento de las personas con las cuales no se tenga afinidad y otros términos son objeto de requerimiento como cualidad sobresaliente para pertenecer al grupo (ejemplo, el típico grupo de las mas buenas del salón, ó el reconocimiento como diablas). 
Abordando la exclusión, aparece la marginalización que ocasiona disfunciones en las conceptualizaciones de la realidad y procurando esquemas rígidos jerarquizados de quien se es. La marginalización implica que ya no se ocupa un lugar aceptado y mucho menos reconocido. "La violencia simbólica opera en tanto el grupo, para su constitución recrea límites implícitos (o explícitos) para la pertenencia al mismo, validando significados e imponiendo nuevas formas de ver la vida”" ${ }^{\prime 5}$. Es así como la violencia simbólica puede entenderse como "la capacidad o poder de hacer que la validez de significados mediante signos sea tan efectiva que otra gente se identifique con ellos". ${ }^{16}$

Las características propias de la adolescencia acentúan terminologías que rotulan actitudes, rasgos físicos o comportamientos, en la medida en que los y las jóvenes buscan la pertenencia, la identificación y el reconocimiento del grupo de pares.

La violencia simbólica es invisible porque se instaura en la naturalización de los roles asignados a hombres y mujeres. Igualmente es violencia porque la fijación en ellos compromete las opciones individuales y la autonomía personal, aspectos que se manifiestan en las construcciones identitarias que las adolescentes adoptan a partir del criterio de otros.

Finalmente, es importante resaltar que el control que ejercen los hombres sobre la sexualidad femenina quizás constituye la principal manifestación de poder en las relaciones de género que se establecen entre los y las adolescentes y que constituye un ejercicio de violencia simbólica, en tanto el cuerpo de las mujeres es expropiado para satisfacción de otros, se desea normativizar la apropiación de su cuerpo y la vivencia de su sexualidad. El cuerpo está en la base de la condición de la mujer, "en nuestra sociedad, tiene dos concepciones: el cuerpo materno que sirve para dar la vida a los otros, y el cuerpo erótico para dar placer a los otros, por tanto, es un cuerpo que no le pertenece" ${ }^{\prime 17}$. Del mismo modo, en la medida en que las adolescentes naturalizan el uso de estas palabras, desarrollan mecanismos inconscientes de sobrevivencia para aceptar y justificar la subordinación y la violencia y por lo tanto, perpetúan su ejercicio.

${ }^{15}$ BOCQUET, N. «Sociologie de la culture Pierre Bourdieu, La domination masculine» En: www.lecture.org/Actes/AL64/edito64.html

${ }^{16}$ BOURDIEU, P. (1994). "Razones prácticas. Sobre la teoría de la acción”. Editions du Seuil. Paris,. Pág. 64.

${ }_{17}$ CAMACHO, G (1996). Mujeres fragmentadas. Identidad y violencia de género. Centro de planificación y estudio sociales CEPALES. Quito. Pág. 116. 